\title{
BENEFICIAMENTO DO QUARTZO HIALINO E LEITOSO PARA OBTENÇÃO DE VARIEDADES GEMOLÓGICAS
}

\author{
Ana Olivia Barufi Franco-Magalhães ${ }^{1}$ \\ Beatriz Alexandra da Silva ${ }^{2}$ \\ Roberta Montê Borges de Paiva ${ }^{2}$
}

\begin{abstract}
Resumo
A combinação de irradiação gama e aquecimento através de tratamento térmico tem se mostrado uma boa alternativa para a obtenção de novas cores em quartzo hialino, que normalmente não possuem aplicação gemológica. Buscou-se neste trabalho a aplicação de irradiação gama em diferentes doses e tratamento térmico, sob temperaturas e taxas variáveis, para a obtenção da tonalidade green gold em amostras de quartzo hialino e leitoso. Estes ensaios foram combinados com análise por Difração de Raios-X, Fluorescência de Raios-X e espectroscopia de absorção na região do infravermelho por transformada de Fourier com o objetivo de se verificar o potencial desses minerais obter esta nova cor. Os resultados obtidos sugerem taxa de dosagem e aquecimento específicos para cada uma das variedades pesquisadas.
\end{abstract}

Palavras-chave: Beneficiamento. Minerais gemológicos. Quartzo.

\begin{abstract}
The combination of gamma irradiation and heating through heat treatment has been shown to be a good alternative for obtaining new colors variety in hyaline quartz colors, which usually do not have gemological application. In this work the application of gamma irradiation in different doses and heat treatment, under variable temperatures and rates, was obtained to obtain the green gold tonality in hyaline and milky quartz samples. These tests were combined with X-Ray Diffraction, X-ray Fluorescence and Fourier transform infrared absorption spectroscopy in order to verify the potential of these minerals to obtain this new color. The results suggest a specific dosage and heating rate for each of the varieties studied.
\end{abstract}

Keywords: Beneficiation. Gemstones. Quartz.

\section{INTRODUÇÃO}

O beneficiamento de minerais gemológicos é considerado qualquer procedimento realizado, que não seja a lapidação e/ou polimento, que vise melhorar a durabilidade, aparência, cor e brilho destes minerais, de forma a agregar valor de mercado.

\footnotetext{
${ }^{1}$ Universidade Federal de Alfenas, Campus Poços de Caldas, Doutor, Professor Adjunto, Grupo de Pesquisa em Recursos Minerais, ana.magalhaes@unifal-mg.edu.br

${ }^{2}$ Universidade Federal de Alfenas, Campus Poços de Caldas, Bacharel em Engenharia de Minas, Grupo de Pesquisa em Recursos Minerais, beee_bb@hotmail.com, beta.mbp@gmail.com
} 
O valor de uma gema natural tratada depende da influência de fatores extrínsecos (exposição às condições naturais de pressão, temperatura e luminosidade) e intrínsecos (presença de inúmeros elementos químicos responsáveis pela cor de um mineral e estrutura cristalina, principalmente), fazendo com que a amostra seja única. A falta do entendimento de como os minerais gemológicos podem ter a sua cor melhorada ou intensificada, ou até a geração de uma nova cor, ocasiona a realização indevida do procedimento de beneficiamento de uma gema, podendo até inutilizá-las. Por outro lado, nos últimos anos tem-se registrado um enorme interesse da indústria joalheira nacional e internacional pelos minerais gemológicos beneficiados, pois, com a aplicação de processos específicos, estes apresentam maior aceitabilidade mercadológica e, como consequência direta, intenso aumento de preço deste material.

Estes processos de beneficiamento consistem em melhorar seu grau de transparência e cor, ou até mesmo, revestir/preencher com resinas, irradiá-las e até tingi-las. Sem dúvida, o aspecto mais valorizado para o mineral gemológico é a cor, pois, representa um papel muito importante na beleza, tradição de mercado e avaliação de uma gema. A capacidade que certas gemas têm em permitir modificações totais ou parciais de suas cores, assim como da uniformidade de suas cores e/ou de seus graus de transparência, quando submetidas a processos de beneficiamento, são questões muito relevantes. Estes processos podem melhorar diretamente a aparência do material pela mudança de cor, da transparência, ou por esconder ou disfarçar imperfeições ou, indiretamente, por produzir uma semelhança com outro material mais valioso. Potenciais minerais-gemas, como o quartzo $\left(\mathrm{SiO}_{2}\right)$, podem sofrer alteração da cor se expostas a irradiação por raios gama, acrescido ou não de tratamento térmico (aquecimento). A aplicação destes processos específicos, porém individuais para cada mineral, podem até gerar uma gema mais barata com cor e aspecto bem próximos à alguma outra bem mais cara. Estas "imitações" também são bem aceitas no mercado, pois, tornam um material, aparentemente sem valor comercial nenhum, viável economicamente.

\section{Quartzo}

Segundo Klein \& Dutrow (2012) aproximadamente 64\% da crosta terrestre é constituído por minerais formados por uma rede tridimensional de tetraedros de $\mathrm{SiO}_{4}$, pertencentes à classe dos tectossilicatos. O resultado desta interação entre Si e O é uma estrutura estável formada por ligação química híbrida (iônica e covalente) na qual a razão $\mathrm{Si}: \mathrm{O}$ é 1:2. A estrutura $\mathrm{SiO}_{2}$ é capaz de ter oito polimorfos, distribuídos em função da temperatura e pressão de formação do ambiente geológico. 
A série dos polimorfos de quartzo é caracterizada por possuir diversas cores, tais como: incolor, roxa, esfumaçada, amarela, preta, rosa, roxa, e apresenta importantes aplicações. Segundo o Anuário Mineral (2014) tais como: areia para moldes de fundição e na construção civil, fabricação de vidro, esmalte, saponáceos, dentifrícios, abrasivos, lixas, fibras óticas, refratários, cerâmica, produtos eletrônicos, relógios, indústria de ornamentos; fabricação de instrumentos óticos, de vasilhas químicas, refratários, etc. É muito utilizado também na confecção de joias de menor valor aquisitivo e em objetos ornamentais, especialmente suas variedades coloridas, configurando-se como mineral de aplicação gemológica.

\section{MATERIAIS E MÉTODOS}

As amostras de quartzo utilizadas nesta pesquisa são procedentes da região de Corinto/MG e foram obtidas por doação pela Cooperativa Uniquartz. São provenientes da unidade geológica Supergrupo São Francisco/Grupo Bambuí, inserido na Província São Francisco, (CPRM/CODEMIG, 2014). Após a caracterização macroscópica, óptica e mineralógica, as amostras no estado bruto foram separadas nas variedades quartzo hialino e quartzo leitoso.

Os experimentos de difração de raios $\mathrm{X}$ em pó foram realizados em um equipamento Shimadzu XRD-6000, usando radiação de $\mathrm{Cu}-\mathrm{k} \alpha$ e um filtro de níquel, velocidade de varredura (goniômetro) de $0.5^{\circ}$ minuto e intervalo de 2 a $80^{\circ}(2 \theta)$, pertencente ao Laboratório de Cristalografia, Instituto de Química, Universidade Federal de Alfenas/MG.

As análises de FTIR foram executadas no Laboratório de Plasmas Tecnológicos da Universidade Estadual Paulista, Campus Experimental de Sorocaba. Esses ensaios foram executados com amostras em pó, no Espectrômetro Jasco FTIR-410 e realizados em temperatura ambiente, com resolução de $4 \mathrm{~cm}^{-1}$ e numa região de comprimento de onda entre $3.018 \mathrm{~cm}^{-1} \mathrm{e} 3.630 \mathrm{~cm}^{-1}$.

As amostras de quartzo, de tamanho entre 3 e $4 \mathrm{~cm}$, foram submetidas a radiação gama com fonte de $\mathrm{Co}^{60}$ no CDTN/UFMG. O quartzo hialino foi irradiado nas dosagens de $200 \mathrm{KGy}$, $300 \mathrm{KGy}$ e $400 \mathrm{KGy}$. O quartzo leitoso, por sua vez, foi irradiado nas dosagens de 100KGy, 300KGy e 500KGy. Com o objetivo de verificar a influência dos parâmetros dosagem, temperatura e tempo de duração do tratamento na mudança de cor do quartzo hialino e leitoso, as amostras foram submetidas a temperaturas que variam entre $150^{\circ} \mathrm{C}$ e $400^{\circ} \mathrm{C}$, com tempo entre 0 e 210 min para as dosagens citadas. Os ensaios de tratamento térmico foram realizados no Laboratório Multiusuário I e II, Instituto de Ciência e Tecnologia, Campus Avançado de 
Poços de Caldas da Universidade Federal de Alfenas/MG. Todas as condições dos experimentos foram direcionadas para a obtenção da tonalidade green gold em amostras de quartzo leitoso e hialino.

\section{RESULTADOS}

\subsection{Análise de DRX e FRX}

Os resultados das análises químicas das amostras indicam que as mesmas são dominadas, principalmente, pelas impurezas Al, Na, Ca, Mg, Cr, K, Fe, Zr e P (Tabela 1).

\begin{tabular}{|l|l|l|}
\hline & Quartzo leitoso & Quartzo hialino \\
\hline $\mathrm{SiO}_{2}$ & 98.68 & 98.86 \\
\hline $\mathrm{Fe}_{2} \mathrm{O}_{3}$ & 0.03 & 0.02 \\
\hline $\mathrm{TiO}_{2}$ & 0.00 & 0.00 \\
\hline $\mathrm{Na}_{2} \mathrm{O}$ & 0.02 & 0.02 \\
\hline $\mathrm{K}_{2} \mathrm{O}$ & 0.02 & 0.02 \\
\hline $\mathrm{CaO}$ & 0.02 & 0.02 \\
\hline $\mathrm{MgO}$ & 0.16 & 0.03 \\
\hline $\mathrm{P}_{2} \mathrm{O}_{5}$ & 0.02 & 0.02 \\
\hline $\mathrm{ZrO}_{2}$ & 0.02 & 0.02 \\
\hline $\mathrm{Cr}_{2} \mathrm{O}_{3}$ & 0.02 & 0.02 \\
\hline $\mathrm{Al}_{2} \mathrm{O}_{3}$ & 0.35 & 0.22 \\
\hline Perda ao fogo & 0.18 & 0.11 \\
\hline
\end{tabular}

Tabela 1 - Análise química das amostras de quartzo hialino e leitoso.

O difratograma de raios- $\mathrm{X}$ das amostras quartzo utilizadas nesta pesquisa apresentam uma alta cristalinidade, porém com certa distinção entre a variedade hialina e leitosa (Figura 2). 

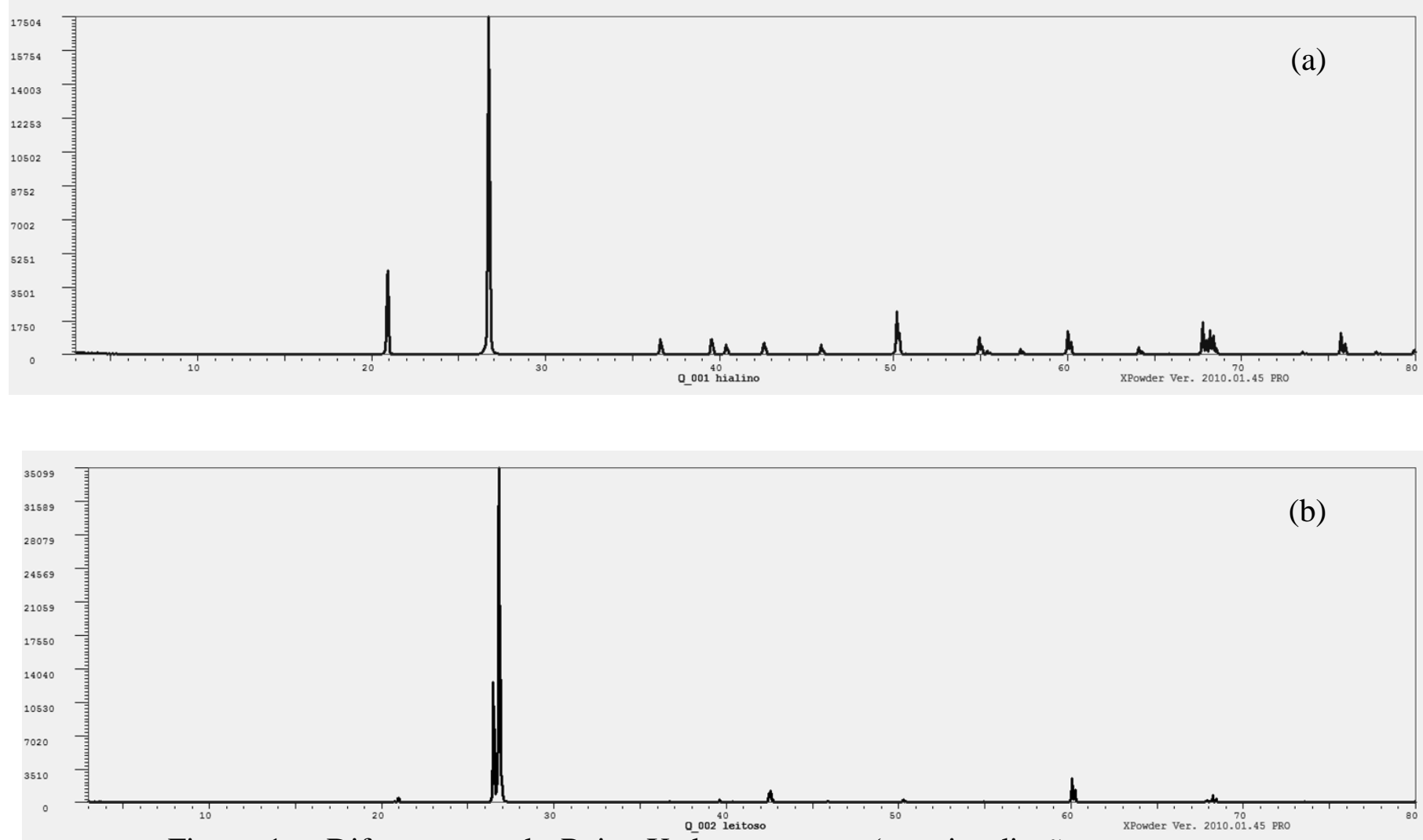

Figura 1 - Difratograma de Raios-X das amostras (sem irradiação e sem tratamento térmico) de quartzo nas variedades hialina (a) e leitosa.

\subsection{Análise de FTIR}

Os espectros de FTIR obtidos para as amostras de quartzo hialino e leitoso, com irradiação e tratamento térmico combinados, encontram-se na Figura 2. De um modo geral, as amostras apresentam curvas com formatos relativamente semelhantes e com registros em três bandas de FTIR, a saber: $3.590-3.600 \mathrm{~cm}-1,3.375-3.380 \mathrm{~cm}-1$ e $3.485 \mathrm{~cm}-1$. 


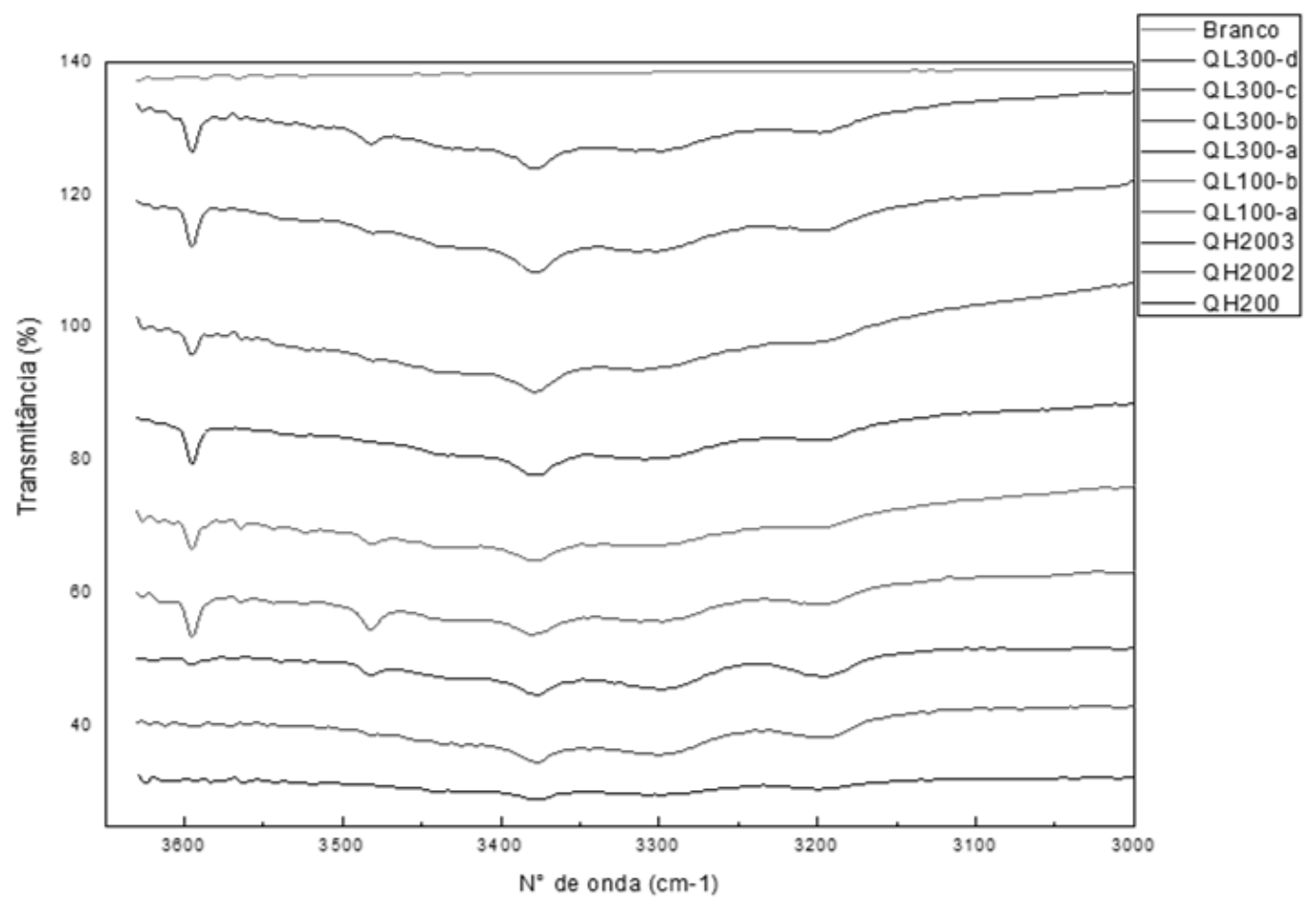

Figura 2 - Espectros de FTIR de amostras de quartzo leitoso e hialino, com e sem irradiação e/ou tratamento térmico.

A banda $3.590-3.600 \mathrm{~cm}-1\left(\mathrm{H}_{2} \mathrm{O}\right.$ tipo II) apresenta registro apenas na variedade de quartzo leitoso. Esta banda é característica da ligação das moléculas $\mathrm{H}_{2} \mathrm{O}$ tipo II. Considerandose que o aspecto leitoso do quartzo desta variedade ocorre em virtude de micro-inclusões de moléculas de água na sua estrutura cristalina, a intensidade de pico desta banda é coerente com a amostra analisada.

É observada também banda em $3.375-3.380 \mathrm{~cm}-1$ em todas as amostras, entretanto com intensidades de picos diferentes, com exceção apenas à amostra QH200, relativa ao quartzo hialino irradiado com dosagem 200KGy. Segundo Drummond et al. (2010), esta banda é indicativa do aparecimento da cor acastanhada.

A banda $3.485 \mathrm{~cm}-1$, por sua vez, apresenta registro apenas nas amostras QH200_3 (quartzo hialino irradiado com dosagem 200KGy, sem tratamento térmico), QL 100_a (quartzo leitoso irradiado com dosagem 100KGy e submetido à uma taxa de aquecimento de $10^{\circ} \mathrm{C} / \mathrm{min}$ por $60 \mathrm{~min}$ em $200^{\circ} \mathrm{C}$ ) e QL 100_b ((quartzo leitoso irradiado com dosagem 100KGy e submetido à uma taxa de aquecimento de $20^{\circ} \mathrm{C} / \mathrm{min}$ por $0 \mathrm{~min}$ em $350^{\circ} \mathrm{C}$ ), neste último menos intenso. Drummond et al. (2010) também observaram este pico em amostras de quartzo hialino 
irradiadas e com tratamento térmico, sendo esta banda indicativa para o aparecimento do matiz amarelado e acastanhado.

\subsection{Tratamento térmico}

Considerando-se as amostras de quartzo hialino, as condições dos ensaios de tratamento térmico ocorreram a uma taxa de aquecimento de $25^{\circ} \mathrm{C} / \mathrm{min}$ para as dosagens de radiação gama de 200KGy, 300KGy e 400Kgy, sob temperatura e tempo variáveis. Com base na Figura 3, pode-se observar uma sutil relação entre o aumento da temperatura e a diminuição do aquecimento, principalmente para faixas de temperatura mais baixas, entre $300^{\circ} \mathrm{C} \mathrm{e} 200^{\circ} \mathrm{C}$, para a obtenção da tonalidade green gold.

A dosagem de 300KGy, ainda para o quartzo hialino, apresenta uma melhor relação de seu comportamento frente ao tratamento térmico, quando comparada à dosagem $200 \mathrm{KGy}$, mesmo com tempo de aquecimento bastante inferior em relação aos demais. Nesta faixa de dosagem, as amostras submetidas à temperaturas mais elevadas apresentaram tempo menor para o tratamento, ou seja, atingiram a tonalidade green gold em menor tempo quando submetidas a temperaturas mais elevadas.

A dosagem 400KGy, por sua vez, é a faixa que apresenta a melhor relação entre tempo e temperatura para as condições aqui definidas. Nesta dosagem, é clara a relação entre o aumento de temperatura e a diminuição do tempo do experimento. Este resultado mostra, de maneira bastante evidente, que quanto maior a temperatura, menor o tempo necessário para que a amostra alcance a tonalidade em questão.

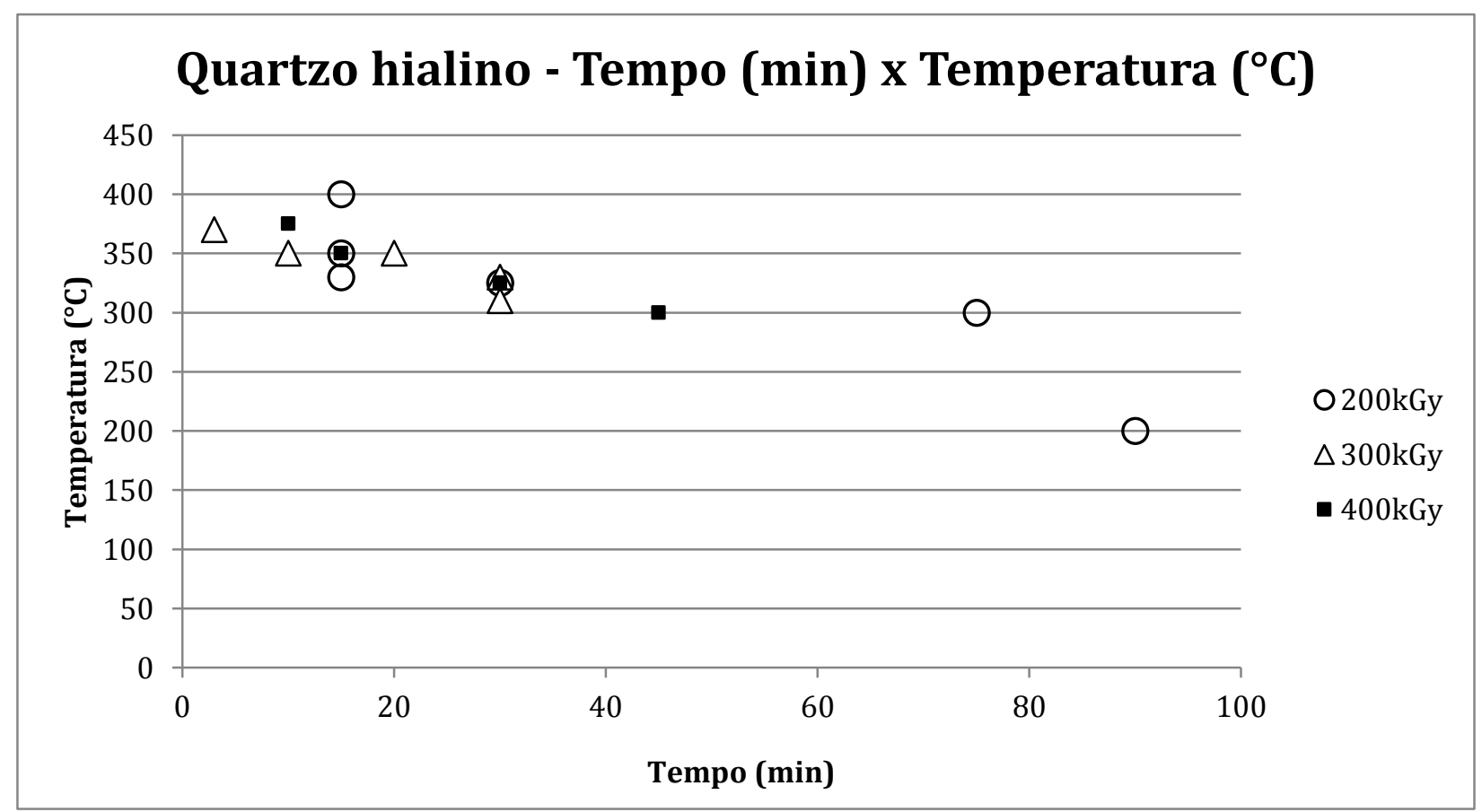


Figura 3 - Condições de tempo e temperatura para descoloração parcial das amostras irradiadas de quartzo hialino até atingir a tonalidade green gold.

Os experimentos realizados no quartzo leitoso ocorreram na faixa de 100KGy (taxa de aquecimento $10^{\circ} \mathrm{C} / \mathrm{min}$ e $20^{\circ} \mathrm{C} / \mathrm{min}$ ), $300 \mathrm{KGy}$ (taxa de aquecimento $20^{\circ} \mathrm{C} / \mathrm{min}$ ) e $500 \mathrm{KGy}$ (taxa de aquecimento $10^{\circ} \mathrm{C} / \mathrm{min}$ e $20^{\circ} \mathrm{C} / \mathrm{min}$ ).

As amostras das faixas de 100KGy e 500KGy submetidas a taxa de aquecimento $10^{\circ} \mathrm{C} /$ min apresentaram comportamento bastante parecidos com relação à temperatura e ao tempo. No caso dos valores de temperatura de $300^{\circ} \mathrm{C}(100 \mathrm{KGy})$ e $400^{\circ} \mathrm{C}(500 \mathrm{KGy})$ a mudança de cor para a tonalidade green gold foi instantânea, ou seja, ocorreu a alteração da cor tão logo o equipamento atingiu a temperatura. No caso de valores de temperatura mais baixos $250^{\circ} \mathrm{C}$ e $200^{\circ} \mathrm{C}$ (faixa de radiação de $100 \mathrm{KGy}$ ) e $350^{\circ} \mathrm{C}, 300^{\circ} \mathrm{C}, 250^{\circ} \mathrm{C}$ e $200^{\circ} \mathrm{C}$ (faixa de radiação de $500 \mathrm{KGy}$ ), ocorreu a mudança de cor em condições de tempo proporcionalmente menores com o decréscimo da temperatura (Gráfico 2). Ressalta-se, entretanto, que dentre essas duas faixas de dosagens, a faixa de 500KGy apresentou melhor comportamento para a mudança de cor perante esta taxa de aquecimento $\left(10^{\circ} \mathrm{C} / \mathrm{min}\right)$.

Considerando-se a taxa de aquecimento de $20^{\circ} \mathrm{C} / \mathrm{min}$, as amostras apresentaram comportamento diferente quando consideradas as condições de tempo e temperatura para diferentes taxas de dosagem (neste caso, 100KGy, 300KGy e 500KGy). A faixa de 300KGy não apresenta uma relação clara entre as variáveis do experimento (Figura 4). A faixa de $100 \mathrm{KGy}$, por sua vez, apresenta mudança de cor para a tonalidade green gold instantânea ou mínima em condições de temperatura elevada $\left(350^{\circ} \mathrm{C}\right.$ e $\left.300^{\circ} \mathrm{C}\right)$. Para as condições de temperatura entre $250^{\circ} \mathrm{C}$ e $150^{\circ} \mathrm{C}$, o tempo requerido para a mudança de cor é maior quanto menor for a temperatura do equipamento. A faixa de dosagem de 500KGy é a que apresenta a melhor correlação entre tempo e temperatura para a mudança de cor aqui proposta. Embora atinja a cor instantaneamente na temperatura de $400^{\circ} \mathrm{C}$, a alteração da cor é observada nos valores de temperatura de $350^{\circ} \mathrm{C}, 300^{\circ} \mathrm{C}, 250^{\circ} \mathrm{C}$ e $200^{\circ} \mathrm{C}$. Neste caso, o tempo é maior quanto menor for a temperatura. Além disso, nesta faixa de dosagem de 500KGy, com uma taxa de aquecimento de $20^{\circ} \mathrm{C} / \mathrm{min}$, observa-se uma relação linear entre as variáveis tempo e temperatura, ou seja, à medida que a temperatura do ensaio é maior, menor é o tempo requerido para a mudança de cor (com exceção apenas da temperatura de $400^{\circ} \mathrm{C}$, na qual a cor é alterada tão logo o equipamento alcance esta temperatura). 


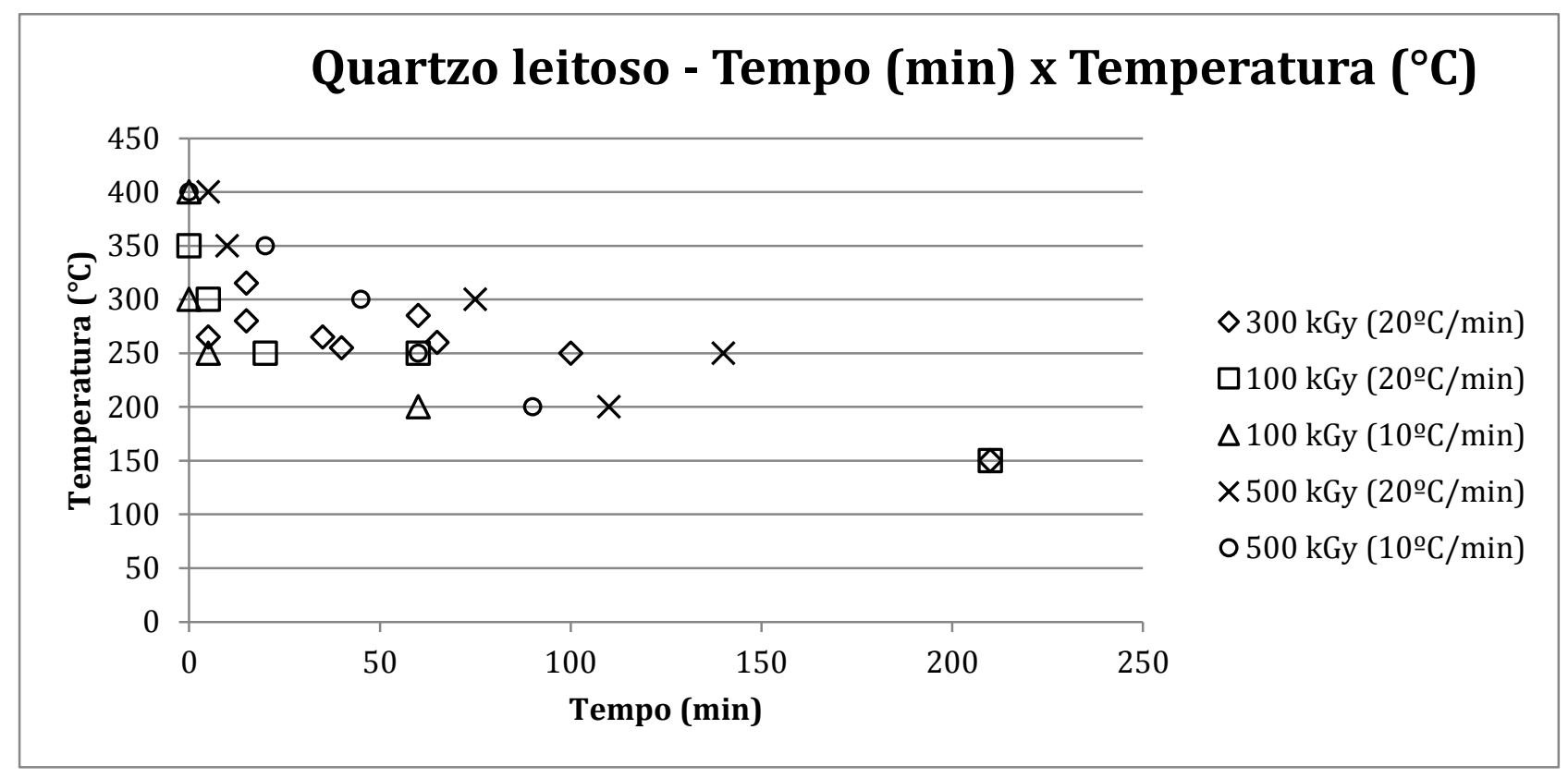

Figura 4 - Condições de tempo e temperatura para descoloração parcial das amostras irradiadas de quartzo leitoso até atingir a tonalidade green gold.

\section{DISCUSSÃO}

Visando a mudança de cor em amostras de quartzo hialino, foram aplicadas as técnicas de caracterização mineralógica (análise mineralógica, FRX, DRX e FTIR) com o objetivo de verificar quais as matizes de cor poderiam ser atingidas com a aplicação da irradiação gama e tratamento térmico.

Com base nas análises e resultados de FRX e FTIR, pode-se concluir que as amostras de quartzo hialino e leitoso aqui tratadas não apresentam, em sua composição química e estrutura cristalina, elementos cromóforos capazes de desenvolver uma nova cor. Segundo Drummond et al (2010), as bandas de FTIR registradas indicam a possibilidade de criação de matizes que variam do preto ao amarelo acastanhado claro, desde que irradiadas e tratadas termicamente. Essas matizes apresentam o nome comercial de morion, green gold, beer, cognac, whisky e champagne. Drummond et al. (2010) associam a criação dessas tonalidades em quartzo de origem pegmatítica e rico em lítio. Os resultados de FRX das amostras utilizadas nesses ensaios não indicam a presença deste elemento químico, mas as matizes de cor foram alcançadas com os mesmos tratamentos.

Considerando-se a combinação de irradiação gama, em diferentes dosagens, e tratamento térmico, sob temperatura, tempo e taxas de aquecimento variáveis, pode-se verificar o potencial 
do quartzo em adquirir as tonalidades green gold, tanto na sua variedade hialina como leitosa. Esta última, inclusive, apresenta importante melhora no seu grau de transparência.

Os ensaios realizados no quartzo hialino irradiado com dosagem 400KGy apresentaram os melhores resultados tanto para a obtenção desta nova matiz como na relação entre tempo e temperatura para as condições aqui definidas. Nesta dosagem, é clara a relação entre o aumento de temperatura e a diminuição do tempo do aquecimento para a mudança de cor.

No quartzo leitoso, entretanto, pode-se concluir que as amostras irradiadas na dosagem de 500KGy apresentaram os melhores resultados para a obtenção da tonalidade green gold quando comparadas com as demais faixas de irradiação. Além disso, foi possível perceber também a mudança no grau de transparência/diafaneidade desta variedade de quartzo quando irradiada. Com a irradiação gama, as micro-inclusões de água, responsáveis por fornecerem seu aspecto leitoso, não se mantêm com o tratamento. Fica evidente que houve mudança de fase cristalina do quartzo leitoso com a irradiação gama seguida de tratamento térmico. Análise de DRX em amostra de quartzo leitoso irradiada e com tratamento térmico confirmou esta alteração de fase cristalina (Figura 5) e os tratamentos aqui apresentados podem ser uma alternativa na utilização desta variedade como gema.

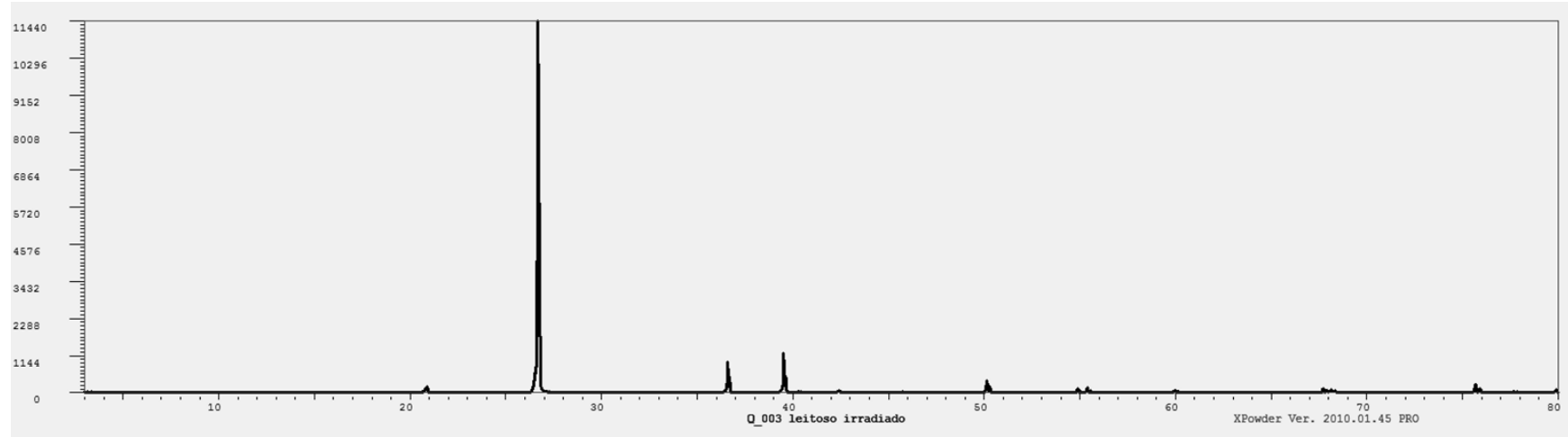

Figura 5 - Difratograma de Raios-X da amostra irradiada e com tratamento térmico de quartzo leitoso

\section{CONCLUSÃO}

As diferentes doses de irradiação aplicadas às espécimes de quartzo hialino e leitoso da região de Corinto (MG) mostraram-se bastante eficientes para a obtenção da tonalidade green gold, para fins de aplicação gemológica. Assim sendo, o melhor resultado obtido para a variedade hialina foi a irradiação com a taxa de dosagem de $400 \mathrm{KGy}$, seguido de tratamento térmico a $375^{\circ} \mathrm{C}$ por $10 \mathrm{~min}$. No caso do quartzo leitoso, o ensaio que apontou o melhor 
resultado foi a irradiação com a taxa de dosagem de $500 \mathrm{KGy}$, seguido de tratamento térmico a $350^{\circ} \mathrm{C}$ por $20 \mathrm{~min}$, com uma taxa de aquecimento de $10^{\circ} \mathrm{C} / \mathrm{min}$.

Por fim, sugere-se que sejam testadas condições sobre o grau de esmaecimento destas amostras, de forma a verificar a estabilidade da nova tonalidade obtida.

\section{AGRADECIMENTOS}

Ao Laboratório de Cristalografia do Instituto de Química da Universidade Federal de Alfenas/MG pelas análises de DRX, ao Laboratório Químico da Togni S/A Materiais Refratários pelas análises de FRX, ao Laboratório de Plasmas Tecnológicos da Universidade Estadual Paulista, Campus Experimental de Sorocaba pelas análises de FTIR e ao CDTN/UFMG pela irradiação das amostras utilizadas nesta pesquisa.

À UNIFAL-MG, pela concessão de bolsa de extensão (Edital 04/2016 - PROBEXT 2017 - Projetos), através do projeto "Desenvolvimento de processos de beneficiamento em minerais gemológicos como subsídio para aproveitamento econômico".

\section{REFERÊNCIAS}

CODEMIG- Companhia de Desenvolvimento Econômico de Minas Gerais. Mapa de Recursos Minerais sobre fundo tectônico. Escala 1:1.000.000. 2014.

Departamento Nacional de Produção Mineral. Sumário Mineral - 2014. Coordenadores Thiers Muniz Lima, Carlos Augusto Ramos Neves. Brasília: DNPM, 2014. 141 p.

Drummond N.F, Mendes J.C., Lameira F.S. Caracterização de quartzo para obtenção de suas variedades gemológicas por irradiação gama e/ou tratamento térmico. REM: R. Esc. Minas, Ouro Preto, 63(3): 449-456, 2010.

Klein B, Dutrow C. Manual de Ciência dos Minerais. 23a ed., Porto Alegre, Artmed Editora S.A. 2012. 706 p. 